\title{
PROFESORADO REFLEXIVO E INVESTIGADOR. PROPUESTAS Y EXPERIENCIAS FORMATIVAS
}

\section{REFLECTIVE AND INVESTIGATIVE TEACHERS. PROPOSALS AND TRAINING EXPERIENCES}

\author{
Ángels Domingo Roget (coord.)
}

Madrid: Narcea Ediciones, 2020.

El libro Profesorado reflexivo e investigador. Propuestas y experiencias formativas, reúne a investigadoras de México, España y Chile que han vertido su experiencia investigativa y docente con la finalidad de eliminar las barreras que la tradición académica ha construido lentamente entre dos actividades que son, en realidad, inseparables: docencia e investigación.

A partir del pensamiento de Donald Schön -quien considera al docente como un investigador en contexto práctico- este libro invita a avanzar en la consolidación de una nueva cultura docente, basada en la indagación y en la investigación en el aula y fuera de ella, como medio para la mejora permanente de la práctica profesional y para la formación de investigadores.

Los textos que conforman este libro parten de la pregunta: ¿cómo ser practicante reflexivo, tanto en la dimensión investigativa como en la dimensión docente? Esta interrogante se atiende a lo largo de los textos escritos por Ángels Domingo Roget, Sara Elvira Galbán Lozano, Claudia F. Ortega Barba, Ana Ayuste González, Montserrat Payá Sánchez, Yazna Silvana Cisternas Rojas y Marcela Jarpa Azagram, distribuidos en cuatro grandes secciones y nueve capítulos, prologados por Miguel Zabalza.

\section{PRIMERA SECCIÓN: HACIA UNA CULTURA BASADA EN LA INDAGACIÓN}

De manera introductoria se plantean los «Rasgos y las habilidades» que requiere un docente-investigador. En el segundo capítulo, «Los modelos para desarrollar una docencia indagadora», se describen propositivamente varios modelos efectivos que propician el desarrollo de la competencia reflexiva en los docentes, a nivel individual, grupal e institucional.

1 Publicación digital. En https://ebooks.narceaediciones.es/library/publication/profesorado-reflexivo-e-investigador-propuestas-y-experiencias-formativas 


\section{SEGUNDA SECCIÓN: ENTRE LA INVESTIGACIÓN Y LA DOCENCIA UNIVERSITARIA. UN ACERCAMIENTO DESDE LA PRÁCTICA REFLEXIVA}

Esta sección incluye dos capítulos. El primero, «De la reflexión sobre el objeto de estudio a la reflexión sobre la práctica de la investigación», establece que aunque la reflexión, de manera natural, la requiere el investigador para configurar su objeto de estudio, es distinta de aquella que lo convierte en un practicante reflexivo; lograrlo supone la sistematización del proceso de reflexión en cuanto al quehacer investigativo. Considerando que el objeto de la práctica reflexiva es la experiencia profesional contextualizada, es que se puede hacer referencia a un investigador practicante reflexivo, pues aun cuando este tiene una profesión en un campo del saber específico (ingeniería, enfermería, sociología, pedagogía), su quehacer se ha decantado por el trabajo investigativo como actividad habitual en la que se ha especializado y, por tanto, esta puede ser materia de práctica reflexiva.

El otro capítulo, «El investigador en el aula universitaria como practicante reflexivo», habla del investigador en el aula, ámbito donde surgen tres escenarios: cuando el profesor investiga sobre su práctica; cuando el docente es profesor de investigación, y el tercero es la del investigador que a la par desempeña el rol de profesor. En este capítulo se analiza el tercer escenario, mostrando cómo el practicante reflexivo debe serlo en sus distintos roles profesionales (en este caso el de investigador y el de profesor).

\section{TERCERA SECCIÓN: LA COMPETENCIA INVESTIGADORA EN LA FORMACIÓN INICIAL DEL MAESTRO}

La educación -entendida como una práctica en constante revisión- y la exigencia de fundamentar los procesos de mejora e innovación en la investigación científica, evidencian la necesidad de formar a los maestros como investigadores. Para ello, se aportan elementos para la reflexión y el debate sobre cómo desarrollar la competencia investigadora en los procesos de formación inicial y, especialmente, sobre los diferentes enfoques y métodos que facilitan su desarrollo a través del encuentro entre universidad y escuela. Lo anterior se despliega a lo largo de tres capítulos que informan sobre el paso "Del maestro reflexivo al maestro investigador», a través de trabajos de investigación aplicada, centrados en los intereses o requerimientos de los centros educativos, como un nuevo servicio que a los estudiantes de magisterio se les pueden ofrecer, a la vez que suponen una vía de formación continua. Los otros capítulos versan sobre «El papel de la investigación en la formación inicial de maestros y maestras» y "La investigación formativa y el codiseño como estrategias metodológicas para el desarrollo de la competencia investigadora», que privilegian la necesidad de formar a los maestros como investigadores, en búsqueda constante por la innovación. 


\section{CUARTA SECCIÓN: ESTRATEGIAS DE REFLEXIÓN PEDAGÓGICA PARA POTENCIAR LA INVESTIGACIÓN Y LA TRANSFORMACIÓN DE LAS PRÁCTICAS DOCENTES EN EL AULA}

Esta última sección contiene dos capítulos sobre estrategias específicas: Los «Círculos de reflexión pedagógica para el fortalecimiento de las competencias investigativas del docente y de su saber pedagógico», cuyo objetivo es comunicar una experiencia de formación continua - para profesores de escuelas públicas-, centrada en el fortalecimiento de la competencia reflexiva, generada a partir del modelo ATOM, para asegurar que el profesorado cuente con experiencias auténticas de discusión y de construcción del saber pedagógico. Y la otra estrategia referida en esta sección es «La escritura reflexiva y su importancia para el desarrollo de un profesor que investiga su práctica docente», que describe la experiencia formativa desarrollada con un grupo de profesores de Educación Primaria que se desempeñan en colegios con altos índice de vulnerabilidad y, por lo tanto, los espacios de investigación y la reflexión pedagógica quedan pospuestos. Se diseñó, entonces, un modelo didáctico que propició el abordaje de la escritura como una herramienta epistémica, facilitando el instalar habilidades para el crecimiento profesional y permitiendo transitar a este grupo de docentes hacia un perfil de un profesor reflexivo, investigador y transformador.

El libro Profesorado reflexivo e investigador. Propuestas y experiencias formativas articula, así, importantes procesos en la práctica docente: reflexionar, enseñar e investigar. Los textos promueven rutas para eliminar las barreras que la tradición académica ha construido lentamente entre dos actividades que son, en realidad, inseparables: la docencia y la investigación. 